\title{
Information and Communication Technologies in Philology Education in Russia
}

\author{
Zolotova Tatiana Arkadjevna \\ Department of Russian and Foreign literature \\ Mari State University \\ Yoshkar-Ola, Russia \\ e-mail: zolotova_tatiana@mail.ru
}

\begin{abstract}
The article considers the main forms of ICT (information and communication technologies) used in Philology education in Russia and presents the experience of development and use of traditional (folklore) culture database as a virtual excursion with game elements in the process of education of Bachelors in Philology of Mari State University.
\end{abstract}

Keywords-ICT; Russia; Philology; distance education; traditional culture; folklore; virtual museum; virtual excursion; virtual guide; game

\section{INTRODUCTION}

Information and communication technologies are rapidly gaining popularity in the sphere of education, including Philology [1]. According to the Russian philologists, ICT (Information and communication technologies) do not only retain their common characteristics in this field but also bring quality changes in it: increase the level of students involvement in the educational process, improve understanding of the studied material, form functional and project literacy, develop theoretical, social, linguistic, and socio-cultural thinking, improve communicational skills, increase the level of social activism, civil awareness and tolerance of students, provide opportunities for selfdetermination etc. [2]. At present ICT functioning in the Philology field considers that an educational institution is to have modern technical equipment, in fact its implementation is usually carried out in the forms of students' use of electronic libraries, special sites dedicated to Philology (online conferences, information exchange), distance learning (training systems, virtual excursions, virtual guides), databases (statistics, frequency dictionaries, corpus linguistics), virtualization etc. [3]. Among them situational game training systems for learning Russian and multimedia educational systems acquire a special significance, e.g. "School of Cyril and Methodius "[4]. It is important that this kind of resources "expand possibilities of working with a text and create background for a deep mastery of linguistic material" [2]. To date, they have identified the most productive models of ICT use in the process of teaching Russian and Russian literature on different levels at the university and high school [2]. Meanwhile we must admit that further development of this field should be in practical and experimental areas.

\section{VIRTUAL MUSEUM OF FOLKLORE}

Russian folklore specialists have interesting innovations in this aspect. Thus, the First All-Russian Congress of folklorists (2006) presented projects that suggested a complex approach to the use of ICT in the process of teaching and research of folklore at the university. The article by T.A. Zolotova and V.S. Izhutkin "Idea of fundamentality to the system of university training in traditional culture" [5] provides a sample of educational website in folkloristics. The main components of the site are: 1) electronic libraries (digitized copies of basic publications in folkloristics); 2) a depository of specific software tools related to information security; 3) computer programs to prepare students for the practice of folklore and further data processing; 4) a database on different genres of traditional and contemporary folklore; 5) original lectures and a database of tests; 6) a depository of graduation projects; 7) a virtual laboratory. Subsequent works of the authors are of interest as well [6]. The next step of the team towards searching possible forms of ICT implementation in teaching folkloristics was the use of computer games [7].

The mentioned approaches were successfully realized in the team's development of the first trendy Russian virtual museum of folklore in the interactive shell. A user becomes fully involved in the process of interaction with a new environment. A museum prototype was presented at the Third All-Russian Congress of folklorists (Moscow, 2014).

The most important thing for the developers was to choose a type of material to open the database of traditional (folklore) culture of Mari El. The participants of the project directed their attention to Yurino region of the republic for many reasons: picturesque location (the left bank of the Volga river, the confluence of two mighty rivers - the Volga and the Vetluga), presence of great architectural structures (Sheremetyev castle and Michael the Archangel Church), dynamic and intense history, expressive type of the Russian population, a peculiar dialect and the richest folk tradition. Much of the material recorded in the region is as great as classical models introduced in famous collections by P.V.Kireyevsky, P.V.Shane, A.I. Sobolevskiy etc.

The materials of the museum are organized as an excursion with game elements. The designers of the game made a building of the museum similar to the famous Sheremetyev castle. The construction of the castle started in 1812 in the style of late Gothic Revival and completed in 
1915. The draft was prepared by R. Muller, A. Stern, A. Parland, A. Korsch, S. Rodionov, P. Malinowski. The owners were Vasiliy Petrovich and Olga Dmitrievna Sheremetyevs. Olga Dmitrievna was a sister of a renowned Russian General, Mikhail Skobelev, who used to visit them. The owners gathered a large collection of ancient firearms and bladed weapons, including personal items of Skobelev, in the castle. There were nearly a hundred rooms in the castle, among them " Art Gallery ", " East Office" , "Oak Room", " Skobelev's room " etc.

The virtual museum uses 5 halls of the castle. However, only one part, namely front door and a luxurious staircase leading to the central part of the castle, remained unchanged, the rest four were filled with new realias by the designers of the project. For example, the hall "Historical Songs" has got portraits of famous historical figures, a click on the portrait of one of them makes you familiar with the contents of the text devoted to him. The hall of ritual folklore provides a wide collection of folk toys (mostly Dymkovo toys), accordingly a click to the figures of a groom and a bride leads to the description of folk wedding traditions, a click to a procession of the characters leads to calendar holidays etc. Various types of harmonicas cover numerous types of folk rhymes etc.

\section{GAMEPLAY AND A FAIRY-TALE GUIDE}

The tour is conducted by Yoshkin cat, one of wellknown characters of the new visual range of the capital of Mari El Republic, who has already become its trademark. (He is represented at the entrance to the main building of Mari State University sitting on a bench). Due to the threedimensional image, made by the developers, the figure of the cat seems alive in the museum: he rises from the bench and comes up to the viewer. Like a true folk mythological character, he starts with a monologue, "My dear friend, do you recognize me? Yes, it's me, Yoshkin cat, the keeper of unique treasures of Mari region. This castle hides one of them. Would you like to see it?" Each collection is prefaced by his remarks. From the one hand, they contain a very concise but accurate description of peculiarities of the collection; on the other hand, the brightest features are highlighted. For example, he opens the collection of a calendar ceremonial and wedding folklore with a remark, "Oh! This hall has a wonderful description of calendar celebrations and wedding customs of Yurino region! It was so much fun, meow... when we celebrated Pancake week here! And at weddings we sang and danced and performed scenes! It turned out the bride wailed... it's a pity, meow", the collection of folk rhymes is prefaced by the phrase, "Here is a huge collection of folk rhymes of Yurino region about love. Some of them are humorous. I like those about an accordionist best! Click a harmonica and you'll hear them!"

There are game elements in the project. Before getting to the world of Sheremetyev castle the viewer (in this case a user) should find a key, i.e. artifacts related to the history, monuments of architecture and daily life of Yurino region. The developers of the database used the gameplay of of "hidden object adventure" games, which requires developers to stick to rules: to focus on prescribing details, to think of nontrivial solution scenes, and mainly to create a special atmosphere which makes a user feel constantly gripped by the tour, though there is no usual game dynamics.

\section{MAIN COLLECTIONS}

The material of the database is represented by a number of collections. As expected, the first hall contains portraits of outstanding performers of Russian folklore of Yurino region and household items of the inhabitants. Clicking a performer's portrait, the user gets detailed information about his or her biography and folkloric works. All text descriptions were compiled by T.A. Zolotova.

The ethnographic collection of the region is presented in a rather peculiar way. It combines visual and verbal aspects. The household items of Yurino region are introduced by L.V. Frolova, the founder and keeper of a real museum located in the region - the "Peasant House" in the village of Vassilyevskoe.

E.g. A user clicks the picture of a loom, it gets bigger and there appears a text,"This is a loom. It was used for producing all necessary household things (towels, tablecloths, fabrics, clothing). By the way, men of Vassilyevskoe were called "red pants" as they wore pants with red stripes on the sides. Our loom is still operating. It has four treadles. See, how many tools we'll need to assemble the loom: big and small gauge rings, sticks to wind the thread. But I can't assemble it myself, I'll need somebody's help. As for weaving a cloth, it seems there's nothing complicated in it."

In the next hall the user gets acquainted with a collection of historic songs. It covers quite rare plots: a song about the consequences of the capture of Kazan by Ivan the Terrible ("Kazan-city"), a song about the Swedish-Russian conflict in 1788 ("Am I still the King of Sweden ..."), a song about the fires in Moscow in 1812 ("Napoleon in Moscow "), a song about the death of Tsar Alexander I in Taganrog (Oh, Alexander was gathering ..."), a song about a successful war between Russia and Turkey 1828-1829. ("Turkish threats").

As for the collection of ritual texts (calendar and wedding), the basic principle of systematization and edition of the material was comparing texts from various settlement groups and defining a universal code on the basis of the results (e.g. the universal codes of Pancake week celebration is visiting a fish market, making a straw man, horse riding, starting feasts, games with newlyweds, burning bonfires) and enriching it with detailed descriptions (samples are arranged in such a way that the most completed and brilliant come first).

The materials of the wedding ceremony of Yurino region are represented in the same manner.

The hall with the collection of folk rhymes brings the tour to the end. They are grouped according to topics (happy//unhappy love, rival love etc.)

\section{CONCLUSIONS}

Thus, the folklorists of Mari El (Russia) have composed and implemented as planned the project of a database on 
traditional culture of Mari El peoples followed by its further uploading in the Internet. It is supposed that it will be a fulltext database (including basic ethnographic description and texts, audio and video ritual materials, actions and other entertainment forms of main ethnics of the republic). This article describes one of its constituent parts, the virtual museum of folklore of Yurino region. The final version of the database will maintain the proposed search system and navigation type, i.e. the materials of other ethnic groups and regions will be placed in the virtual museum with game elements in the similar way (for each region and ethnos there will be a particular museum suitable for this or that area). The participants suppose that in future they will manage to represent the material on a high technical level with the use of modern design, trendy computer graphics, which, in turn, should enhance the status of Russian information resources among the youth and arouse their interest in national traditional culture and folklore.

\section{REFERENCES}

[1] E.I. Vishtinetzkiy, A.O. Krivosheev, "Information technology issues in education and training", Information Technology, 1998. № 2. pp. 32-37; I.G. Zakharova, "Information technology in education", Moscow, 2003, p.192 ; V.P. Bespalko, "Education and training with computers (Education science of the Third Millennium)", Moscow, 2008, p.352; Network of creative teachers Teachers council. http://www.orghttp://pedsovet.org/; Open class http://www.openclass.ru/ etc.; "Use of information and computer technologies in educational process and problems of its methodological support", [electronic resource] http://www.eidos.ru/journal/2006/0901-5.htm; Electronic journal "Information and communication technologies in teacher education", [electronic resource]: http://www.journal.kuzspa.ru/

[2] [electronic resource]: http: // www.openclass.ru/node/78809/

[3] [electronic resource]: http: // www.mindmeister.com/117231621/_

[4] [electronic resource]: http://www.km-school.ru/

[5] T.A. Zolotova, V.S. Izhutkin, "Idea of fundamentality to the system of university training in traditional culture", vol. II, The First AllRussia Congress of folklorists, Moscow, 2006, pp.345-353.

[6] T.A. Zolotova, V.S. Izhutkin, "New information technologies and teaching folklore", Newsletter of Udmurtia University, 2008. № 5-1 pp.161-168; T.A. Zolotova, "Information technology in educational projects on folklore studies", Innovations based on information and communication technologies, 2008, №1, pp. 318-320.

[7] N.I. Vassilieva, P.I. Efimov, T.A. Zolotova, "A playing man: a picture of the world in the subculture of gamers", Internet and folklore, collection of articles, Moscow, 2009, pp. 202-208; N.I. Efimova, T.A. Zolotova, "The knights of virtual reality: some design patterns of computer game characters", Folklore XXI century: Heroes of the present time, collection of articles, Moscow, 2013, pp. 225-234. 